\title{
Looking beyond the local
}

\section{Equity as a global concern in Early Language Learning}

\section{Janet Enever}

Umeå University \& King’s College London

\begin{abstract}
Around the world, the popularity of English has escalated, particularly at the primary school level (Butler, 2015), yet provision of sufficient qualified teacher expertise to meet demand continues to be inadequate. The OECD report on Equity and Quality in Education reports that: "The highest performing education systems are those that combine equity with quality. They give all children opportunities for a good quality education" (OECD, 2012). This paper adopts a sociohistorical perspective to critically examine the OECD criteria of achieving equity and quality through fairness and inclusiveness with reference to Uruguay, India and China - all contexts where English has been introduced at primary and kindergarten levels. The analysis draws on data from classroom observations, interviews with teachers and key stakeholders. Findings indicate that while access to the quality provision of English in primary schools and kindergartens has been substantially expanded in recent years in each jurisdiction, the challenges of ensuring universal quality provision have proved complex under conditions where the pre-existing historical and political contexts have limited progress towards equity.
\end{abstract}

Keywords: Early Language Learning, global, equity, political

\section{Introduction}

The challenges of achieving equity in terms of English language provision (second or foreign) at primary school level worldwide are daunting. Political, social and/ or economic factors most often work against achieving and sustaining equity. As an illustration of the range of provision in a country such as India, the following contrasting snapshots offer some sense of the part played by both socioeconomic and political factors in this context. Firstly, picture a beginners' class 
of 46 children (aged 6 years). The room is equipped with well-worn wooden desks arranged in rows, the children have paper and pencils, but no books. A blackboard is propped against one wall, with the teacher writing individual words using poor quality chalk which seems to produce a great deal of chalk dust. The lesson in progress is the weekly English lesson in this Hindi-medium school, yet very little English is spoken, either by the teacher or pupils. In the lesson observation it soon becomes apparent that this teacher had only an elementary level of English. This government-funded school was in need of substantial further investment if an acceptable level of quality was to be achieved in English language provision. In contrast to this, in a high-end private school in another city, children could be observed working in small groups in a classroom equipped with a wide range of books, poster displays and various language support materials. In one group, seated at a modern hexagonal table arrangement, children were listening to a story in Tamil, read aloud by a classroom assistant. In another corner children were collaborating on the construction of a model, whilst, in a third, children were grouped in twos and threes, collaboratively writing stories in English. In this classroom the teacher mainly adopted the role of facilitator, assisting the various groups in organising their own learning and generally ensuring that all children were engaged in effectively carrying out their tasks.

The fact that such contrasting situations exist in India, a huge country which has only relatively recently introduced a policy of compulsory education for all children from 6-14 years (Government of India, 2009), is unsurprising given an estimated population size of over 1.3 billion (World Bank, 2016), a large proportion of which lives in rural regions which have suffered from under-investment in education for many years. By way of comparison, we might anticipate that equitable provision in Europe should look rather different, given that compulsory schooling across the majority of European countries was fully established prior to 1920 (Soysal \& Strang, 1989), and the population size is considerably smaller (approximately 750 million; UN, 2017).

Despite the huge difference in scale between India and Europe, questions of equity in education are similar, often substantially affected by the global forces of neo-liberalism and "shaped by a range of transnational forces and connections" (Rizvi \& Lingard, 2010, p.3). This paper focuses on three main concerns for equity in education pertinent to the provision of primary English: firstly, an increased urban-rural divide, particularly with regard to school attendance; secondly, gender equality (both in terms of access and subject choices); and thirdly, access to digital technologies with high quality connectivity. Acknowledging the broader aims of education in achieving good outcomes and ensuring quality throughout the system, these themes are critically examined with reference to the contexts in focus. The contexts of Uruguay, India and the Shanghai region of China are 
selected for particular features in the provision of English illustrative of the contemporary complexities in achieving equity. Data was collected by the author during a number of studies conducted from 2014-2018.

\section{A brief history of primary foreign languages provision}

In many countries early schooling was initially established through the support of religious groups. This provision was subsequently adopted by state institutions in their efforts to provide mass education systems free for all (Boli, Ramirez, \& Meyer, 1985). Parallel with these developments, wealthy families often employed personal tutors for their children, continuing with the provision of an elite education by sending their children to private schools. In this way forms of class divide have been established which continue to play a central role in some educational contexts today. One significant strand of elite provision in many parts of Europe and beyond, was the introduction of additional languages (both ancient and modern) from the age of 7-8 years. The intention here was to prepare the young person for a future cosmopolitan lifestyle in which they might expect to read great literature in other languages, also to travel and converse with others of a similar background (as documented by Charlotte Bronte in various of her novels).

From these early beginnings of elite provision a global trend for introducing foreign languages (FL) in state school systems has developed, firstly at secondary school level and, quite recently, in the early primary school years. Increasingly today national education policies include compulsory FLs with required introduction in the first two or three years of primary education. Even in contexts where a particular FL is not specified, the most favoured choice is English, generally promoted on the basis of an argument that proposes fluency in English will improve a country's economic advantage, providing a labour force equipped to engage in international business.

Alongside this trend, a number of former British colonies (e.g. India and the regions of the Indian sub-continent; a number of African countries, etc.) where English was previously the medium of instruction (EMI) during colonial times, have maintained or (re)introduced their commitment to providing English from the early phases of schooling (either as EMI or as a separate subject). The provision of EMI in such contexts has proved extremely controversial, given the strong evidence for educational failure in both African and Indian contexts, as a result of the former colonial policy (Annamalai, 2005; Batibo, 2014). Attempts to replace English with a widely spoken indigenous language in government schools have had varying degrees of success, while private schools have often maintained an EMI policy as a marketing tool for the elite. In India, the 
increasingly global use of English as a lingua franca has also recently precipitated the setting-up of privately-run EMI schools, with limited or no regulation, specifically catering for the demands of English by the poorer sectors of society (Bhattacharya, 2013), offering what Mohanty, Panda \& Pal (2010, p. 216) describe as a 'cosmetic Anglicization'.

In summary, it can be proposed that children attending primary schools around the world today, between the ages of approximately 5/6 years and $11 / 12$ years, may expect to receive some instruction in English, whether as a subject or as EMI. In some regions of the world there has also been substantial growth in the provision of English classes at the kindergarten / pre-school level, particularly in the private school sector (Rokita-Jaśkow \& Ellis, 2019). The impact such provision has on broad education provision in terms of both quality and equity is reviewed in the following sections.

\section{Conceptualising equity in education}

In a discussion of education policy and globalisation, Rizvi and Lingard (2010,p.76) propose that equity in education is concerned with "who gets what, when and how?" Elaborating on this definition they argue that education systems today are shaped by a very narrow definition of equity, principally concerned with issues of access to educational opportunities and failing to address the broader historical and political contexts that produce disadvantage in the first place' (p.157). They propose that through a focus on the Millennium Development Goals (MDG) (UN, 200o) contemporary definitions of equality have been framed in terms of universal access to primary schooling, gender equality in education, and ensuring access to information technology in education, with the aim of overcoming "the digital divide" (p.153). However, in establishing these timebound, measurable targets there is an assumption that access alone will produce social justice. This position ignores the historical conditions which continue to define quality of provision and fail to seriously address what conditions might actually contribute to success. They conclude that, as such, the MDG adopts 'a very weak definition of the concept of justice (p.157).

Rizvi and Lingard's (2010) account confirms the importance of drawing a distinction between the terms equality and equity - terms which are often used interchangeably. The following front cover illustration from the Handbook on Measuring Equity in Education (UNESCO, 2018) clarifies the distinction by emphasizing that equality may offer equal access to education, but a prerequisite for facilitating equity in terms of educational outcomes is to ensure an equal starting point for all learners (Figure 1). 


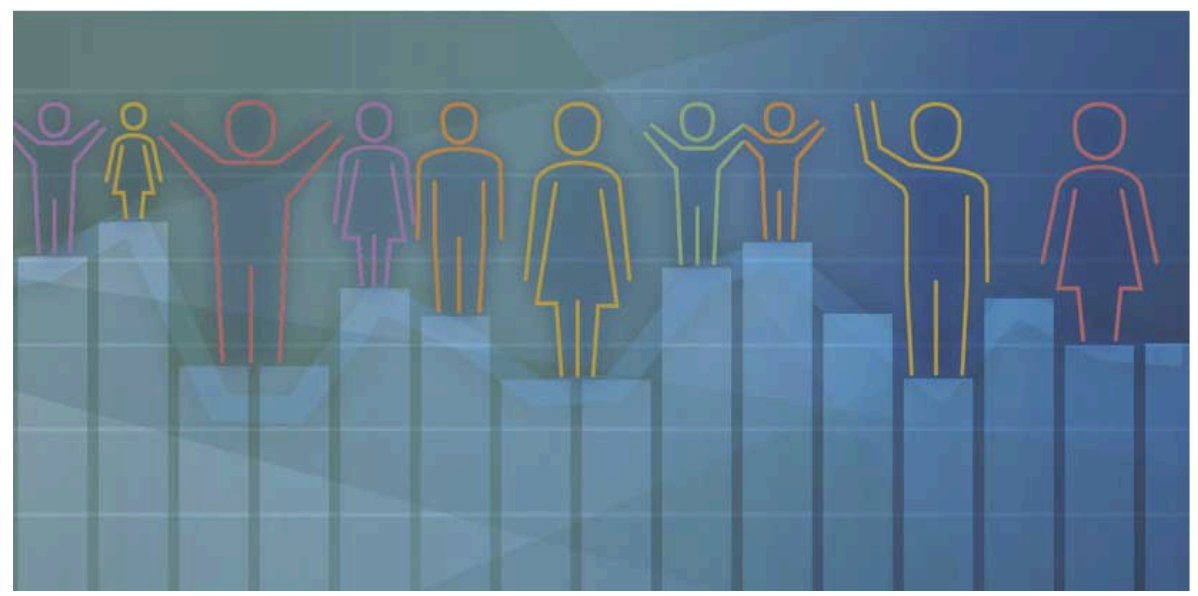

Figure 1. Equity and the potential for equal outcomes (adapted from cover illustration, Handbook on measuring equity in education, UNESCO, 2018)

Key actors and influencers of policy in national education systems today can be identified as: World Bank (WB), International Monetary Fund (IMF), Organisation for Economic Cooperation and Development (OECD) and the United Nations (UN), including the UN family of UN Development Programme (UNDP), UN Educational, Scientific and Cultural Organisation (UNESCO) and UN International Children's Emergency Fund (UNICEF). Through mechanisms such as technical advice, partnership projects and conditional loans these international bodies have frequently operated in concert, establishing an agenda which prioritises the importance of education in contributing to the future market value of a well-trained labour force, paying little or no attention to the potentially negative impact on societies that may ensue.

A series of UN initiatives have emphasized the importance of providing universal primary education. These included the Millennium Development Goals (UN, 2000), the UN Sustainable Development Goals (SDG) (UN, 2015a), Declaration on the Future of Global Education until 2030 (UNESCO, 2015), and the UNESCO Global Education Monitoring Report (GEM) (UNESCO, 2016). Of relevance to the discussion of equity, the SDG goal 4 places emphasis on the provision of "free equitable and quality primary education" with "all girls and boys [having] access to quality early childhood development, care and pre-primary education". Also included is a commitment to improving education facilities to provide access and safety for all and the goal of substantially improving the supply of qualified teachers with the assistance of international cooperation. The SDG sets a target for the achievement of these goals by 2030 . Continuing with this theme, the GEM Report (UNESCO, 2016) proposes a 
detailed procedure for annual monitoring of progress towards equity including measures for: gender, disability, language, migration and forced displacement. However, in the section on Equity, the difficulty in capturing evidence of how historical inequities contribute to lower school achievement is acknowledged (UNESCO, 2016, p.259), reflecting Rizvi and Lingard's concerns discussed above. More broadly, the report emphasizes the design limitations for indicators which attempt to make comparisons between countries with quite different geographical, economic and cultural characteristics.

Following the GEM Report (UNESCO, 2016) a Handbook providing guidance for the measurement of progress towards equity in education at national level has been published (UNESCO, 2018) with the aim of prioritizing this as a global imperative. The Handbook proposes an examination of inequity 'from different angles, including inputs, processes, outputs and outcomes, as well as in various contexts (e.g. education systems, providers and learners)' (UNESCO, 2018, p.12). Much weight is given to the potential for improving equity through redistributive policies whereby "the most disadvantaged should receive the largest share of government resources and pay the least out of their own pockets" (UNESCO, 2018,p.124). Referring back to the GEM Report the authors list the areas where redistribution should be focused as related to: "gender, disability, forced displacement (...) diversity along cultural, linguistic and ethnic lines, (...) poverty [and] residency (...)" (p.70).

It is clear from the above discussion that efforts to ensure an equal starting point for all learners are now being seriously addressed - at least by supranational agencies such as the UN. In the following sections of this paper these issues are considered with reference to national policy and local provision of English as a second / foreign language at primary school and kindergarten levels in the contexts of Uruguay, India and China.

\section{Equity and digital technology in Uruguay}

\section{Uruguay national curriculum background}

In 2012 the small Latin American country of Uruguay embarked on a radical plan to provide English as a foreign language (EFL) for learners throughout the country from year 4 (age 9) with classroom tuition via a digital connection to a remote teacher based somewhere else in the world. This initiative was part of a much wider plan to reform the education system with the aim of "providing high-quality education, ensuring educational continuity from the beginning of the formal educational process, at pre-school level, until the end of the upper secondary education" (ANEP, 2017, p.11). 
The planned reforms bear the hallmarks of influence from recently documented global educational priorities such as those listed in the GEM Report (UNESCO, 2016). In the case of Uruguay, the National Curriculum Reference Framework (ANEP, 2017) identifies the following aspects as a priority: education as a human right; inclusive provision for all learners from pre-school to upper secondary school (3-18 years) and provision of student-centred learning which meets the diverse needs of all learners, particularly those in disadvantaged contexts such as geographically remote areas and low socio-economic circumstances. Threaded throughout the document is an emphasis on establishing education as a democratic principle which prioritises equitable provision. The following section provides a short summary of the historical and contemporary languages spoken in Uruguay to clarify the linguistic context further.

\section{A brief historical perspective on language and language planning in Uruguay}

Bertolotti and Coll (2014,p.102) provide detailed accounts of language use across the Uruguayan region from the period prior to colonisation up to the present day. Reportedly, prior to the first contacts with Europeans in the sixteenth century, a number of indigenous languages were spoken including Charrúa, Chaná, Güenoa and Guaraní. With European settlement and subsequent colonisation came the spread of new diseases, warfare, genocide and inter-marrying between the indigenous people and Spanish colonisers, resulting in the disappearance of all indigenous languages by the mid-nineteenth century. From this period Spanish became the de facto language of Uruguay, although a form of Portuguese was spoken close to the border with Brazil (known as Portugués del Uruguay), together with other European languages brought by settlers, including Italian, German, French, Russian and English. A number of African languages also arrived as a result of slave trade (Canale, 2015, p.19).

Evidence of concerted efforts for language-in-education planning emerged with the publication of the General Education Law (MEC, 2008, p.7) which explicitly referred to Uruguayan Spanish, Uruguayan Portuguese, Uruguayan Sign Language and the teaching of second and foreign languages in schools. While this document can be seen as top-down national planning for languages, it also recognised the position of regional varieties, significantly emphasising the importance of plurilingualism / multilingualism. This signalled an increasing awareness of the complexity of language planning, acknowledging the potential benefits that might ensue as a result of adopting a consultative process. In similar vein, the report of the Commission on Language Policy (ANEP, 2008) confirmed a plan to include English in the primary school curriculum. Here, English was positioned as offering new opportunities for all, representing English as 'empowering' in the sense 
that all citizens should have a democratic right to a twenty-first century education. According to Canale (2015, p. 31) "more than 120 stakeholders (teachers, coordinators, administrators, policy makers, etc.), and around 12 institutions" were involved in the design of the 2008 curriculum - a procedure which can be seen as predicated on democratic principles.

\section{Current provision for primary foreign languages in Uruguay}

Following the decision to introduce English in primary schools a substantial national budget was allocated to establishing provision throughout the country with the aim of achieving full coverage by 2020 . Two pathways to provision were identified. Firstly, a continuation of the already-established pre-service teacher education programme (known as Segundas Lenguas) and secondly, via the innovative use of interactive video conferencing, connecting classrooms to specialist primary English teachers located remotely (anywhere in the world where suitable technical hubs are made available). The pathway for primary English teachers trained in the Segundas Lenguas programme has proved effective, with qualified teachers able to offer English from year 1 (6 years) in 317 primary schools in 2017 (Kaplan \& Brovetto, 2019,p. 29). However, teacher supply is very limited, hence, the provision via video conferencing has now been expanded to reach an additional 536 primary schools by 2017 (Kaplan \& Brovetto, 2019,p.29). The video conferencing solution was selected partly because it was already in use in schools for a number of other projects, thus easing the implementation of innovative technology.

Following an initial piloting period in 2012 (Banegas, 2013), provision was rolled out firstly to regions of the country where household income was generally lower, then subsequently to all urban regions of the country. Finally, the remaining rural regions for which it has proved more difficult to provide high quality digital interconnectivity are currently being addressed - with digital provision where possible or with the availability of upskilling opportunities for locallybased teachers elsewhere. Recent figures reflecting national provision indicated that approximately 95 percent of all urban primary schools were able to provide good quality English language teaching in years 4, 5 and 6, 70 percent of which was provided by videoconferencing and 30 percent by face-to-face teaching (Plan Ceibal, 2017). Further solutions for the provision of primary English in rural contexts where digital connectivity is poor have been sought more recently. These have included transporting children from a rural school to the nearest available urban school with remote teacher provision (Escuela Amiga programme); linking schools using Cisco Jabber software to a teaching point with standard videoconferencing facilities (Kaplan \& Brovetto, 2017,p.29) and a weekly e-coaching 
initiative in rural schools for teachers with a minimum intermediate level of proficiency. However, given the remoteness of some primary schools in Uruguay, often with school populations of less than 10 pupils, more than 900 teachers remain yet to be reached (interview with V. Dubini, 13 October, 2018). Nonetheless, the introduction of these complex solutions reflect a national commitment to facilitate equality of opportunity in learning English for all primary school learners across Uruguay.

Given the challenges of achieving national provision it is encouraging to note recent evidence of learning outcomes in English tests of vocabulary, reading, grammar and listening of at least A2 level have been achieved. In tests conducted with a sample of a little over 50 percent of all learners in Years 4, 5 and 6, approximately 70 percent of the learners tested in Year 6 reached an A2 level in late 2017, in both the face-to-face and remote teaching contexts. It should be noted however that writing achievements were somewhat lower and no assessment of oral communication was conducted (Plan Ceibal, 2017, p.10). Overall, this evidence indicates good levels of achievement in both strands of provision.

\section{Measuring equity in primary foreign language provision in Uruguay}

From the moment of an announcement in 2006 that low cost laptops would be provided for every primary school child and their teachers, together with high speed fibre optic connections in all primary schools, claims for a digital revolution in Uruguay became a reality. The opportunity to include English as a foreign language via a system of remote teachers and blended learning offered another step towards equity when the programme was launched in 2012. To some extent, the much-heralded "democratisation of education" including "access to English as a foreign language in the primary education sector" (Brovetto, 2011, p.38) has been achieved through initiatives which appear to have captured the imagination of much of the population and inspired many additional innovations. In addition to the impact on families of having a laptop computer regularly brought home from school by their children, opportunities for the wider community to receive introductory lessons have been provided at local centres around the country. Reportedly, access to new technologies has facilitated new learning opportunities for "members of lower income communities", including the possibility now for grandparents to communicate with their grandchildren online (Cyranek, 2011, p.159).

In fulfilling the aim of overcoming the so-called 'digital divide' Uruguay has sought to address issues of modernity through the provision of digital technologies and opportunities to learn English as a part of primary education. Notably, the administration has engaged in a steady programme of implementation, setting realistic targets which are regularly reviewed to ensure effective implementation. 
Concerns for satisfactory provision in remote rural areas continue to be a challenge, as is serious deprivation in some socio-economically disadvantaged regions. The priority of 'directing resources to students with the greatest needs' (OECD, 2008) is a central focus, but the multiple historical factors which have contributed to disadvantage are likely to take time to fully overcome.

In an acknowledgement of the importance of achieving equity, Miguel Brechner (Plan Ceibal president), in a report documenting the achievements of Plan Ceibal, claimed, "[w]e have built equity in access to devices and internet, as well as access to platforms that improve learning such as the digital library, the study of English, mathematics, robotics and programming" (Brechner, 2017,p.10). In similar vein, Rovengo (2019, p.119) documents "access to English language instruction to students in primary state schools" which was previously only available for those who could afford private education. She reports that, "Ceibal en Inglés reaches schools in underprivileged areas across the country [where the teaching team] adjust the lesson plans and teaching to suit the particular needs of students". In like fashion, there has been a strong commitment to meet individual special educational needs (SEN), with the adoption of an inclusion policy where special needs are catered for in the mainstream classroom. Data indicates that some 85 per cent of remote teachers report having at least one SEN child in the classes they teach.

It is clear from the above evidence that achievements in Uruguay have substantially addressed their aim of overcoming the perceived digital divide, with attempts to complete universal provision of EFL at primary level now close to success. However, reflecting on Rizvi \& Lingard's (2010) concerns for addressing historical injustices and the distinction drawn by the UNESCO (2018) between equality and equity, it seems that the focus in Uruguay, so far, has been rather more on equality than equity. This focus will need to be sharpened through further redistributive policies as they move towards meeting the 2030 SDG goals (UNESCO, 2016).

\section{Equity and free primary education in India}

\section{Background of primary education provision in India}

According to Annamalai (2005) education in precolonial times was made available by local rulers or wealthy and powerful people in different regions of India. Education was provided according to the perceived needs of particular groups of people following the hierarchical structure of society. The medium of instruction depended on the caste, with the Brahmins taught through Sanskrit, Pali used for 
Buddhist monks and the local language for people "engaged in farming, trade and artisan work" (Annamalai, 2005, p. 20).

During the various colonial periods education policy was more centralised, with the aim of educating colonial subjects, equipping them to assist in the process of colonial government. With the period of the British Raj (1858-1947) a new elite was established, educated in English permeated with European knowledge and values. Beyond this elite, it was intended that most of the population should have access to education in their local languages, funded by the government. However, according to Annamalai (2006) this policy was poorly supported and limited in its application.

Following independence, the colonial structures formed a template for a national system of education comprising an elite private schooling system conducted through the medium of English, together with a national system conducted in the regional language. Kumar (2016) reports that since the 196os there has been substantial expansion in the provision of elementary education, paralleled by the growth of private schools, which has led to "the better-off sections of the urban society" choosing to send their children to private schools. As a result, government schools are more often populated by the children of economically disadvantaged families.

Government policy in India officially states that free primary education is a basic right for all children. This policy was formally established by the introduction of the Right of Children to Free and Compulsory Education Act (RTE) (2009). However, the process of achieving effective implementation continues to be a challenge in many regions of the country. The scale of migration throughout India has rapidly increased during the 21st century, with features of both family seasonal and inter-state migration, resulting in a major impact on children's school attendance (Chandrasekhar \& Bhattacharya, 2018). A range of solutions are now proposed at national level. These include: flexible admission, seasonal hostels, transport support, mobile education volunteers and improved coordination of education records for individual children. The RTE act also aimed to create opportunities for first generation learners to enter school and complete a minimum of eight years of schooling. However, a recent report (RTE, 2018, p. 21) notes that the "half-hearted execution of these provisions under SSA (Sarva Shiksha Abhiyan/ Education for All) has meant that India has not been able to deliver quality education to these children". Although the official enrolment rate at primary schools was recorded in 2015 as reaching almost 100 percent (RTE, 2018, p.11), dropout rates at primary level in 2016-17 were recorded as 6.35 percent, with the scheduled castes and scheduled tribes recording the highest dropout rate (officially designated groups of historically disadvantaged peoples). 
Alongside these, children from Muslim communities were most likely to dropout at the transition point from primary to upper -primary level.

Following the principles of inclusion intended by the RTE Act, the Rights of Persons with Disabilities Act (RPWD) (2016) was brought in to ensure the inclusion of children with disabilities in mainstream schooling through the adaptation of school buildings to provide access and enable full participation in education. Little real progress has been made in this however. For example, only 22.22 percent of schools have suitably adapted toilets and some 62.09 percent have provided a ramp (RTE, 2018, p.22).

A number of factors have contributed to the considerable dropout rates including, general under-funding for the implementation of the RTE, lack of funding provision to support teacher education, teacher appointments and poor washing / toilet facilities at many schools. According to the RTE, 2018 Report this underfunding can be related to "a growing thrust by the Government to privatize school education" (p. 20) with proposals for voucher schemes and suchlike, in line with concepts often found in countries with neo-liberal policy agendas.

On a more positive note, some recent measures are being taken by State governments to alleviate the prejudice surrounding girls' education in traditionally patriarchal communities. For example, in Rajasthan projects to encourage reading development, interest in science and maths among girls, together with opportunities for learning self-defence have contributed to the empowerment of girls (RTE, 2018, p.31).

\section{A brief historical perspective on language and language planning in India}

Canagarajah (2009,p.5) notes the existence of a plurilingual tradition in South Asia since precolonial times, describing plurilingualism as "natural to the ecology of South Asia". In similar vein, a national focus group on the teaching of Indian languages commented that "multilingualism is constitutive of the Indian identity" (NCERT, 2006,p.20), with a 1971 Census recording "a total of 1,652 languages belonging to five different language families”. Despite this extensive multilingualism, leaders of the newly-independent republic proposed that Hindi should be designated as the national language (Annamalai, 2005), a viewpoint strongly challenged by the southern states of India where Hindi was not widely spoken.

Following many debates at local, regional and national level, agreement was finally reached by the Kothari Commission (1964-66), recommending a ThreeLanguage Formula (TLF) for the purposes of education., whereby each State identified an official State language (which generally became the medium of instruction in schools). Hindi and English were also to be taught in schools, with varying curriculum time and points of entry for each language according 
to individual State policy. National guidelines have continued to emphasise the importance of maintaining local languages alongside the TLF requirements, as reflected in guidance on expected learning outcomes at the elementary stage suggesting that, "English is learnt best if it is learnt along with and not at the cost of other languages." (NCERT, 2014, p.39).

\section{Current languages provision in Indian primary schools}

Officially, all government-funded primary schools in India are expected to teach the curriculum in the state / regional language, with English taught as a separate subject area. However, despite this national guidance, parental pressure for the provision of a more intensive model of English has escalated during the 21st century. Increasingly, the demand for provision of English Medium Instruction (EMI), is coming from the poor to lower middle class groupings, hoping to gain the same economic advantages that the more privileged sectors of Indian society have acquired through access to high-end EMI private schooling (Kumar, 2016). In this section I report on two recent studies, illustrative of the challenges currently faced by primary schools where the demand for EMI is substantial.

Firstly, a study by Nair (2015) reports on primary schooling outcomes in the southern Indian state of Andhra Pradesh drawing on data collected as part of the Young Lives longitudinal study (2000-2015). Drawing on data sets of primary school learners in EMI and Teluga medium schooling (the State language) Nair compares learning outcomes in school Maths tests, for these two cohorts, adjusting for the socio-economic and community effects in evaluating the significance of the MOI. Findings revealed that students attending Teluga medium schools were generally disadvantaged by attending schools with fewer infrastructure facilities and further disadvantaged by their lower nutritional levels in comparison with students attending EMI schools. When the data was controlled for such factors however, students attending Teluga medium schools achieved more highly than those attending EMI schools.

A further study conducted in the neighbouring southern Indian state of Tamil Nadu revealed many difficulties experienced by government-run Tamil medium schools (the State language) in providing quality English lessons as a part of the curriculum (Enever, 2018). Data collected across a variety of primary schools in the urban region of the capital (Chennai) and surrounding semi-rural districts revealed a range of English language expertise in schools with the majority of teachers operating at approximately an A2 level according to the CEFR (Council of Europe, 2001). With notable exceptions, teachers in many schools relied heavily on the text book, adopting a pedagogy described by Bhattacharya (2013,p.166) as "transmitting scholastic English", implying an emphasis on reading and writing 
with little or no authentic interaction. Elsewhere, in African school contexts Chick (1996) has recorded similar evidence, describing the procedure as a pedagogy of 'safetalk' whereby the teacher reads aloud a section from the book, then asks questions which allow only routine responses, thus limiting the potential for mistakes and for any element of creativity or authentic interaction.

Interviews with school principals and with the co-director of Education for Tamil Nadu revealed the extent to which the demand for EMI has recently escalated. Increasingly, parental aspiration for the perceived benefits of EMI has resulted in even relatively poor rural families choosing to send their children to low-fee privately-run EMI schools. Given this dramatic increase in demand, the State has taken the radical decision of encouraging primary schools to become EMI schools, in the hope that this will help stem the tide in the growth of private (for profit) schooling. It was expected that by 201850 percent of all government and government-aided schools in Tamil Nadu would become EMI schools (personal communication, 21 February, 2015). These statistics reflect a quite astonishing increase, given national figures of approximately 10 percent reported in 1999 (NCERT, 1999, Chapter 11, in Annamalai 2005, p. 25). However, it is important also to acknowledge that the officially reported national figures do not take account of unrecognized schools, so it is likely that already by 1999 the actual proportion of private schools was somewhat higher.

In support of the policy initiative encouraging the growth of government EMI schools in Tamil Nadu the Ministry of Education is providing in-service courses for the 60,000 primary teachers over a ten-year period. The challenge is substantial for teachers, moving away from a pedagogical approach which Annamalai (2005, p.27) describes as "bookish with minimal communicative potential" where children are expected to learn to imitate, rather than to interpret texts. Slowly, as the professional development courses begin to have impact, local primary schools may have access to a pool of well-qualified English teachers.

\section{Evaluating equity in primary languages provision in India}

The legacy of a colonial past has had a severe impact on perceptions for the value of English in India today. Global forces have combined with neoliberal tendencies in the 21st century to allow a market-oriented education system to emerge, with English perceived as essential cultural capital for future economic advantage. The result is one of double disadvantage, whereby those attending elite EMI schools learn to place little value on the culture embedded in their regional languages and those attending government funded schools have limited access to English so may never attain a level of fluency sufficient to enter the so-called global market place. Also in the mix, are those children attending low- 
cost private EMI schools, operating purely for profit and offering very limited access to English. Thus, as Kumar (2016,p.68) argues, "the division of children into two streams, both of which have their own peculiar disadvantages, means a deep imbalance and chronic conflict".

The introduction of the Right to Education Act in 2009 aimed to overcome many of the disadvantages experienced by children from poorer socioeconomic backgrounds. In addition to making schooling for all young people aged 6-14 years compulsory and free the Act also required all fee-paying schools to allocate 25 percent of school places to children from lower socioeconomic backgrounds. Inevitably, given the complexity of monitoring the effectiveness of implementation, some schools have sought out ways to work around or avoid the requirements. The enactment of the RTE continues to have limited impact with less than 10 percent full compliance recorded in 2017/8 (RTE forum, 2018). Basic facilities such as toilets, drinking water and washing facilities were recorded as available in only 53 percent of schools.

Government provision of education in India is substantially under-funded, amounting to less than 3 percent of GDP in 2017. This is compounded by a lack of utilisation of allocated funding, substantial neglect of teacher education and relatively poor learner outcomes, lending support to government arguments for the promotion of privatisation of schooling. Given the current situation, it is difficult to see how a position of equity will be achieved in Indian primary education in the foreseeable future, despite India's claimed commitment to the UN Sustainable Development Goals (UN, 2015a).

\section{Equity in language education for Shanghai kindergartens}

\section{Kindergarten provision in Shanghai}

Until recently, kindergarten provision in China has not been a priority, with no statutory requirement for publicly-funded provision of any type of Early Childhood Education and Care (ECEC) provision. The rapid growth of migration to the cities has further escalated demand resulting in headlines proclaiming a critical shortage in the availability of both kindergartens and qualified kindergarten teachers. Privately-run kindergartens, both for profit and for charitable purposes, have expanded particularly in the rural western regions of China. In efforts to improve provision the government has set a target of ensuring that all Chinese children have access to a minimum of one year's publicly-funded ECEC provision by 2020 (Hu, Zhou, Li, \& Roberts, 2014). Recent government reports suggest that 50 percent public provision, or low-cost private provision of three-year kindergartens will be achieved by 2020 with plans for 100 percent by 2035 (Zou Shuo, China Daily, 2019). 
The Shanghai region has fully acknowledged this priority, no doubt partly precipitated by the presence of many migrant workers from across China who are now contributing to the region's success as a global financial hub. With substantial budgetary commitment the region now has 72 percent publicly-funded ECEC provision with the highest national enrolment rates of 98 percent (accounting for both public and private ECEC provision) (Center on international education benchmarking, 2019).

China operates a restrictive residency system for the allocation of entitlement to schooling, requiring children to undertake education in the region where their family is registered. For the children of migrant workers in cities such as Shanghai this restriction has proved unworkable, given parental expectation for families to stay together and have access to free or low-cost education facilities. The Shanghai government has now taken the initiative to permit the children of migrant workers to attend publicly-funded ECEC provision (Center on international education benchmarking, 2019). According to Minxuan Zhang (president of Shanghai Normal University) migrant children in Shanghai are now likely to be fully entitled to participate in publicly-funded education by 2024 (Tucker, 2014, p.7).

\section{A brief historical perspective on language and language planning in China}

From the establishment of the People's Republic of China (PRC) in 1949 the government has engaged in a series of initiatives to establish Mandarin Chinese (known as Putonghua in Chinese) as the national language. This has included various attempts at script and spelling reforms in an effort to improve literacy rates, together with a policy requirement that Putonghua should be the medium of instruction in all schools (Spolsky, 2014).

Close ties with Russia from the late 194 os led to Russian being the most widely taught foreign language. However, a breakdown in political relationships between the PRC and Russia led to a decline in the popularity of Russian and a rise in the promotion of English as a prestigious foreign language (Feng, 2009). English became the dominant foreign language taught in schools from the late 1970s, with a number of other foreign languages being taught, including Russian (Spolsky, 2014). The rise in the popularity of English reached new heights when it was introduced in year 3 of primary schools (age 9 years) in 2001. The initial programme focused on the urban centres of the coastal region and key political centres of power. From this starting point the programme was to be rolled out to more rural areas over time (Wang, 2009). However, this has proved challenging, given the extreme shortage of qualified teachers in some regions, resulting in many poorer communities still having no provision for English at primary level today. 
In addition to foreign languages, the role of regional and minority languages has gained in recognition, with the 2001 Language Law listing "appropriate occasions" when this might be permitted (Spolsky, 2014, p. 168). Zhou (2012,p.5) identifies typical occasions in which regional or minority languages might be used as in, "markets, hospitals and government offices", with Putonghua being used more in public domains than private. Most recently however, the forces of migration to the cities has led to the more limited use of some regional and minority languages. In Shanghai and elsewhere the rising middle class have expressed concerns about this potential loss of cultural heritage and identity, represented in local news headlines proclaiming a "dialect crisis" with tags such as "saving Chinese dialects" (Gao, 2015, p. 471). These issues are discussed in the following sections, drawing on evidence of language practices across a range of Shanghai kindergartens.

\section{Current languages provision in Shanghai kindergartens}

With a population in excess of 26 million and a total of 1,591 kindergartens registered in the Shanghai region in 2017 (Shanghai Statistical Yearbook, 2018), evidence presented in this section can only be considered as a partial view of present realities. This section reports on classroom observations, field notes and interviews conducted across a range of kindergartens in the Shanghai region in 2016. Access to kindergartens was arranged through the personal connections of an academic with expertise in the field. Inevitably, it is likely that access was facilitated for those kindergartens considered to be of a good standard.

Language policy in Shanghai requires English to be introduced as a subject from Grade 1 of primary school. Kindergartens are expected to use Putonghua as the medium of instruction. However, although a required curriculum for all kindergartens exists, a 20 percent allowance is available for kindergartens to introduce a local curriculum. Increasingly in Shanghai, kindergartens have taken this as an opportunity to introduce English, generally with a 20-30 minute lesson each week. According to Yu and Ruan (2012) this trend has grown substantially since the early 21 st century. Some kindergartens also find it important to include opportunities for the maintenance of regional varieties. For example, in one kindergarten an activity conducted in Shanghainese was observed; while in another a weekly lesson was conducted in a mix of Putonghua and Jinshan district dialect. Interviews with school principals revealed a variety of responses to the question of whether it was appropriate to introduce regional varieties in the curriculum. Two samples are included here to illustrate responses to official policy (pseudonyms are used for all kindergartens to preserve anonymity). 
Lotus kindergarten principal: "If a child uses Shanghainese in school, the teacher replies in Putonghua and the child quickly learns that they should stick to the school language - Putonghua".

Rose kindergarten principal: "Children's home languages include Putonghua, Shanghainese, Jingshan, Changdong, Jiansu and Cantonese. In school we teach Putonghua, Shanghainese, Jingshan and English".

Further questioning revealed the extent of teachers' awareness of home languages with teachers at the Lotus kindergarten declaring no knowledge of home languages. In contrast, the following languages were listed elsewhere:

Mandarin kindergarten: Shanghainese, Japanese, Korean and various European languages.

Rose kindergarten: Shanghainese, Jingshan, Changdong, Jiansu and Cantonese. Camelia kindergarten: Romanian, English, Hanan, Fujan, Cantonese, Shanghainese, Korean and Indian English.

In the observed kindergartens English was taught by a specialist English teacher, with high level fluency and a generally communicative pedagogical approach. Lessons were taught to half-classes of approximately 15 children, with good pacing and a developmentally appropriate variety of activities, including songs, games and TPR activities. Observations were conducted in one low-fee private kindergarten which revealed something of the contrasting pedagogical approach. A distinction between an individualised approach and a collective approach to learning was particularly evident in observations of successive language lessons conducted in English and in Putonghua with a group of 15 boys aged 5 years. Firstly, the native English-speaking teacher (a UK qualified primary teacher) conducted a quick-fire question and answer session in English, inviting individual children to respond to questions about activities they enjoyed at home with their families. This was followed by some more general questions about favourite sports and other activities, with opportunities for anyone to contribute if they felt confident. This 15-minute session was immediately recognisable as a type of informal conversation activity which might be observed in many UK primary schools at the start of the school day, following a weekend perhaps. Children were seated informally on the floor, with no particular seating organisation. The sense of attention to individual contributions was much in evidence throughout the session.

Following this, the native Putonghua-speaking teacher took over (a Chinese qualified primary teacher). This 15-minute session was to be conducted more formally than the previous, with the teacher beginning by instructing children to sit on chairs, forming a semi-circle. Individual cards were then handed out, each bearing a Chinese character representing opposites such as height (tall/short); 
age (old/young); emotional state (happy/sad). Children were invited to read out their characters then change places to sit next to their opposite character. This was followed by a series of further readings of the characters (in order of opposites) and culminating in the creation of a group poem along the lines of: 'I am tall and he is small and we are friends', continuing around the group. In this activity, the strong emphasis on the collective sense of group identity was clearly in evidence.

Morley and Glazzard (2013) conducting observations in Beijing kindergartens comment more generally on a tendency towards a whole class, didactic approach to learning, with only limited evidence of play and exploration in a context which facilitated active learning. They conclude that there was a need for professional development opportunities focusing on "extending children's development through play-based learning" (p.43). This was confirmed by data collected in the author's study in Shanghai kindergartens, indicating that pedagogical approaches generally followed a similar pattern of whole group, teacher led tasks, of a type more likely to be observed with slightly older children in the formal setting of primary schools in many European countries.

Evaluating equity in primary languages provision in Shanghai kindergartens

Three central issues regarding equity have emerged in the literature related to kindergartens in Shanghai; firstly, insufficient supply of low-cost, high quality kindergartens has resulted in queues and long waiting lists, which place an additional burden on those parents at the lower end of the pay scale. For example, the China Daily newspaper reports that parents find themselves spending up to one third of their monthly salaries on kindergarten fees (Zou Shuo, 2 January, 2019). Further concerns relate to the limited supply of fully qualified kindergarten English teachers. According to Yu and Ruan (2012, p.63) there is a severe lack of teachers qualified to teach English to kindergarten children. A survey conducted some time ago by Cui and Yuan (2006) found that only 20 percent of kindergarten English teachers were qualified kindergarten teachers. While no doubt the ratio has improved considerably since then, a severe shortage still exists, with the posts being filled either by English teachers trained to teach older children or by generalist kindergarten teachers with no specific preparation for teaching foreign languages.

Related to the above, some authors have expressed concern about the limited amount of free play opportunities in Chinese kindergartens. While this undoubtedly reflects a European cultural perspective on ECEC, these concerns may also be relevant to the introduction of both English and regional / minority languages. A study conducted in kindergartens in England (Sylva et al. 2004, p. 6) offered the findings that, "Freely chosen play activities often provided the best opportunities 
for adults to extend children's thinking. It may be that extending child-initiated play, coupled with the provision of teacher-initiated group work, are the most effective vehicles for learning." Some combination of language play and teacherinitiated group work might provide a developmentally appropriate introduction to language learning, placing an emphasis on creativity in meaning making as a solid foundation for the more formal context of school language learning.

\section{Discussion and conclusions}

This final section of the paper returns to the concerns of equity introduced above. The challenges of determining "who gets what, when and how?" as identified by Rizvi and Lingard (2010) are complex, particularly given the limitations of national and regional budgets and the historical inequities to be overcome. Nonetheless, it is evident that for each of the jurisdictions discussed in this paper attempts to achieve equity in the provision of early foreign language learning have been met to some extent. These will be summarised below, with reference to the SDG (UN, 2015), overlaid with the additional expectations for social justice recommended by Rizvi and Lingard (2010).

In terms of universal access to digital technologies and foreign language education at primary school level, commitment to these targets has been impressive in Uruguay. From the investment in the provision of low-cost laptops for all primary school pupils in 2008 to 2019 a digital revolution has evolved, with pupils now using digital technologies as an integrated part of learning across the curriculum and almost all primary school pupils having regular access to quality English language teaching. The remaining hard-to-reach rural communities are currently being addressed, with solutions likely to be found in the near future.

The challenge of addressing historical conditions which have resulted in disadvantage are complex and likely to take time and further investment. While official levels of poverty have fallen considerably over the past ten years, rated at $8.1 \%$ in 2018 (World Bank, 2019), poverty is greater in the northern region of the country and particularly among the African descendant population. According to a UNICEF report (2017a,p.2) there is a need for raising "public awareness on situations related to equity, inclusive education, early childhood development and violence affecting the fulfilment of children's rights." Provision of ECEC facilities is far from universal and there continues to be a need to establish quality kindergarten facilities in many parts of the country. Support for schools in adopting policies of educational inclusion for children with disabilities is also considered a priority. With the maintenance of political stability the country has moved forward in addressing historical issues of inequity in education and is receiving 
support from both internal and external agencies in overcoming the remaining obstacles to meeting the SDG goal 4 for education (UN, 2015).

Priorities in India have been somewhat different from those for Uruguay, given the extreme geographical and climatic diversity of the country, the huge scale of population (approximately 1.3 billion), the range of linguistic and cultural diversity, the historical extremes of wealth and poverty and the market-oriented neoliberal policies of the current national government.

India's deep-seated patriarchal norms of power have restricted the rights and opportunities for girls in respect of life chances. However, a number of actions are now being taken, including the implementation of a nationwide ECEC policy, projects to improve attendance rates at secondary school level for girls and to reduce a long-standing tradition of child marriage (UNICEF, 2017b). With regard to primary schooling, the Government of India (2016) reports a net retention rate for children attending primary schools of 67.3 percent (2014/15), with a national plan of action to achieve 100 percent attendance by 2021. Further statistics record substantial numbers of out-of-school children in the age group 6-14 years, amounting to over six million in 2014 (Government of India, 2016, p.72).

Achieving equity in foreign languages provision in primary schools is challenging under conditions of poor attendance, gender disparity, low quality teacher education provision and limited societal understanding for the value of conducting education in the local / State language through the early years of schooling. However, the national action plan for improving ECEC provision and quality (Government of India, 2016) indicates a multi-agency commitment to the UN, 2030 Agenda for Sustainable Development (UN, 2015) which could result in substantial improvements to current provision. Inevitably, such initiatives rely on maintaining political will at all levels over a prolonged period, together with a substantial financial commitment.

In contrast to the above contexts, the ECEC context of China functions under a very different political model. The Communist framework at both national and regional levels operates a strongly centralised model for all primary schools and kindergartens, with a set curriculum framework prioritizing Putonghua as the required medium of instruction. Recent investment in both kindergarten and primary school education quality has occurred mainly in the east coastal cities and other key cities, with less attention given to ensuring the availability of welltrained teachers in the western regions of the country.

Shanghai's strong economic development has resulted in an expanding middle class with expectations for the provision of English even at kindergarten level, despite the official policy. In addition, there is increasing demand for the support of regional varieties and dialects. Partly, these new demands can be attributed to the high percentage of recent migrant arrivals, often with the inclusion of grand- 
parents in the family home, caring for the children, while both parents participate in the booming economy. Concerns that children may no longer be able to communicate with their grandparents have highlighted the significance of cultural and linguistic loss. The response from kindergartens is varied, dependent on the decision of individual school principals. In summary, while the current languages policy for Shanghai kindergartens emphasises the maintenance of Putonghua as medium of instruction for education, a flexible attitude towards the introduction of both English and regional Chinese varieties has been permitted in recognition of "the rising importance of the rights of individual citizens" and "the need for the state to accommodate these in order to maintain political hegemony" (Gao, 2015 p.469). Ultimately however, these practices have resulted in an inequitable languages policy in the region.

The three jurisdictions discussed in this paper illustrate the complexities of achieving equity in the provision of early language learning under conditions where the broader historical and political contexts have contributed to disadvantage. Initiatives for universal access, efforts to improve gender equity and the widespread access to digital technologies have been critically examined, with evidence indicating the need for substantial further actions if social justice for all is to be achieved.

\section{References}

ANEP. (2008). Documentos de la comisión de políticas lingüisticas en la educación pública (Documents of commission on language policy for public education). Uruguay: Administración Nacional de Educación Pública.

ANEP. (2017). Marco curricular de referencia nacional. Uruguay: Administración Nacional de Educación Pública (ANEP) (English translation Federico Brum). Available at: <https:// mcrn.anep.edu.uy/sites/default/files/Documento\%20MCRN\%2oagosto\%202017.pdf> (20 November, 2019).

Annamalai, E. (2005). Nation-building in a globalized world: Language choice and education in India. In A. M.Y. Lin \& P.W. Martin (Eds.), Decolonisation, globalisation, language-ineducation policy and practice (pp. 20-37). Clevedon: Multilingual Matters.

Annamalai, E. (2006). India: Language situation. In K. Brown (Ed.), Encyclopedia of language \& linguistics (2nd ed., Vol. 5, pp. 610-613). Oxford: Elsevier.

https://doi.org/10.1016/Bo-08-044854-2/04611-3

Banegas, D.L. (2013). ELT through videoconferencing in primary schools in Uruguay: First steps. Innovation in Language Learning and Teaching, 7(2), 179-188.

https://doi.org/10.1080/17501229.2013.794803

Batibo, H.M. (2014). Searching for an optimal national language policy for sustainable development. In H. McIlwraith (Ed.), Language rich Africa. The Cape Town language and development conference. Looking beyond 2015 (pp. 16-20). London: British Council. 
Bertolotti, V., \& Coll, M. (2014). Retrato lingüístico del Uruguay. Un enfoque histórico sobre las lenguas en la región. Universidad de la República, Uruguay: Comisión Sectorial de Educación Permanente. Available at: <http://udelar.edu.uy/eduper/wp-content/uploads /sites/29/2015/o9/retrato.pdf> (20 November, 2019).

Bhattacharya, U. (2013). Mediating inequalities: Exploring English-medium instruction in a suburban Indian village school. Current Issues in Language Planning, 14(1), 164-184. https://doi.org/10.1080/14664208.2013.791236

Boli, J., Ramirez, F.O., \& Meyer, J.W. (1985). Explaining the origins and expansion of mass education. Comparative Education Review, 29(2), 145-170. https://doi.org/10.1086/446504

Brechner, M. (2017). Prologue. In Plan Ceibal (Eds.), 10 años Plan Ceibal: Hicimos historia haciendo future (10 years of Plan Ceibal: We made history by making the future) (p. 10). Montevideo: Plan Ceibal.

Brovetto, C.A. (2011). Alcances y limitaciones del uso de tecnologías para la enseñanza de inglés en educación primaria [Scope and limitations of the use of technologies for the teaching of English in primary education]. In L. Behares (Ed.), El V encuentro internacional de investigadores en políticas lingüísticas [Fifth International meeting of researchers in language policy] (pp. 37-41). Montevideo, Uruguay: Asociación de Universidades Grupo Montevideo.

Butler, Y.G. (2015). English language education among young learners in East Asia: A review of current research. Language Teaching, 48(3), 303-342. https://doi.org/10.1017/So261444815000105

Canagarajah, S. (2009). The plurilingual tradition and the English language in South Asia. In L. Lim \& E.L. Low (Eds.), Multilingual, globalising Asia. Implications for policy and education. AILA Review, 22, 5-22.

Canale, G. (2015). Mapping conceptual change: The ideological struggle for the meaning of EFL in Uruguayan education. L2 Journal, 7(3), 15-39. Retrieved from: <https://cloudfront .escholarship.org/dist/prd/content/qt7x30w26x/qt7x30w26x.pdf> (8 September, 2018).

Center on International Education Benchmarking. (2019). Shanghai, China: Supporting equity. Retrieved from: <http://ncee.org/what-we-do/center-on-international-educationbenchmarking/top-performing-countries/shanghai-china/shanghai-china-education-forall/> (2o November, 2019).

Chandrasekhar, S., \& Bhattacharya, L. (2018). Understanding the scope of the challenge and moving towards a coherent policy framework for education for seasonal migrants at the state level in India (Background paper for Global Education Monitoring Report 2019). Retrieved from: <https://unesdoc.unesco.org/ark:/48223/pfoooo266057> (20 November, 2019).

Chick, J.K. (1996). Safe-talk: Collusion in apartheid education. In H. Coleman (Ed.), Society and the language classroom (pp. 21-39). Cambridge: Cambridge University Press.

Council of Europe. (2001). Common European Framework for Languages: Learning, teaching, assessment. Strasbourg: Council of Europe.

Cui, X., \& Yuan, A. (2006). 对目前国内幼儿园双语教育中存在偏差的分析及对策的研究 [The analysis of current issues in bilingual education in kindergartens and solutions]. 外 语艺术教育研究 [Journal of Foreign Language Education], 1, 64-67.

Cyranek, G. (Ed.). (2011). Plan Ceibal in Uruguay. Montevideo, Uruguay: UNESCO. Retrieved from: <http://www.anep.edu.uy/anep-old/phocadownload/Publicaciones/Plan _Ceibal/plan\%2oceibal\%2oin\%2ouruguay.pdf> (20 November, 2019). 
Enever, J. (2018). Policy and politics in global primary English. Oxford: Oxford University Press.

Feng, A. (2009). English in China. Convergence and divergence in policy and practice. In L. Lim \& E-L. Low (Eds.), Multilingual, globalising Asia. Implications for policy and education. AILA Review, 22, 85-103.

Gao, X. (2015). The ideological framing of 'dialect': An analysis of mainland China's state media coverage of 'dialect crisis' (2002-2012). Journal of Multilingual and Multicultural Development, 36, 468-482. https://doi.org/10.1080/01434632.2014.943234

Government of India. (2009). Right of children to free and compulsory education act (RTE). New Delhi, India: The Gazette of India. Retrieved from <http://mhrd.gov.in/sites/upload _files/mhrd/files/upload_document/rte.pdf > (28 August, 2018).

Government of India. (2016). National plan of action for children, 2016. Ministry of Women and child development. Retrieved from: <https://wcd.nic.in/sites/default/files /National\%2oPlan\%2oof\%2oAction\%202016.pdf> (20 November, 2019).

$\mathrm{Hu}$, B., Zhou, Y., Li, K., \& Roberts, S. K. (2014). Examining program quality disparities between urban and rural kindergartens in China: Evidence from Zhejiang. Journal of Research in Childhood Education, 28(4), 461-483. https://doi.org/10.1080/02568543.2014.944720

Kaplan, G., \& Brovetto, C. (2019). Ceibal en Inglés: Innovation, teamwork and technology. In G. Stanley (Ed.), Innovations in education. Remote teaching (pp. 28-35). London: British Council.

Kumar, K. (2016). Education, conflict and peace. New Delhi: Orient Blackswan Private.

MEC. (2008). Ley general de educación. Ley No. 18.437 [General education law. No. 18,437], Ministerio de Educación y Cultura. República Oriental del Uruguay. Montevideo: Dirección Nacional de Impresiones y Publicaciones Oficiales.

Mohanty, A. K., Panda, M., \& Pal, R. (2010). Language policy in education and classroom practices in India. Is the teacher a cog in the policy wheel? In K. Menken \& O. Garcia (Eds.), Negotiating language policies in schools: Educators as policymakers (pp. 211-231). New York, NY: Routledge.

Morley, G., \& Glazzard, J. (2013), Kindergartens in China: A report into private and state provision in Beijing. Early Years Educator (EYE), 13(12), 38-44. https://doi.org/10.12968/eyed.2012.13.12.38

Nair, P.S. K. (2015). Does medium of instruction affect learning outcomes? Evidence using young lives longitudinal data from Andhra Pradesh, India. PERI ESP Working Paper Series, 68, 7-35. Retrieved from: <https://www.younglives.org.uk/content/does-mediuminstruction-affect-learning-outcomes $>$ (20 November, 2019).

NCERT. (1999). Sixth all India education survey. Main report. New Delhi, India: National Council of Educational Research and Training.

NCERT. (2005). National curriculum framework. New Delhi, India: National Council of Educational Research and Training.

NCERT. (2006). National focus group on the teaching of Indian languages. Position paper. New Delhi, India: National Council of Educational Research and Training.

NCERT. (2014). Learning indicators and learning outcomes at the elementary stage. New Delhi, India: National Council of Educational Research and Training.

OECD. (2008). Policy brief. Ten steps to equity in education. Paris: OECD.

OECD. (2012). Equity and quality in education. Supporting disadvantaged students and schools. Paris: OECD. 
Plan Ceibal. (2017). Adaptive assessment of English language in the Uruguayan educational system - 2017. Executive summary. Montevideo, Uruguay: British Council.

Rizvi, R., \& Lingard, B. (2010). Globalizing education policy. Abingdon, UK: Routledge.

Rokita-Jaśkow, J., \& Ellis, M. (2019). Early instructed second language acquisition. Pathways to competence. Bristol: Multilingual Matters.

Rovegno, S. (2019). From classroom teacher to English teacher. In G. Stanley (Ed.), Innovations in education. Remote teaching (pp. 58-60). London: British Council.

RTE Forum. (2018). Status of implementation of the right of children to free and compulsory education act, 2009 (2017-18). Report. Retrieved from: <http://www.careindia.org/wpcontent/uploads/2018/12/Status\%2oreport18.pdf> (20 November, 2019).

Shanghai Statistical Yearbook. (2018). Education. China: China Statistical Press.

Soysal, Y.N., \& Strang, D. (1989). Construction of the first mass education systems in

Nineteenth-Century Europe. Sociology of Education, 62(4), 277-288. https://doi.org/10.2307/2112831

Spolsky, B. (2014). Language management in the People's Republic of China. Language, 9o(4), 165-179. https://doi.org/10.1353/lan.2014.0075

Sylva, K., Melhuish, E., Sammons, P., Siraj-Blatchford, I., \& Taggart, B. (2004). The effective provision of pre-school education (EPPE) project. Sure Start. Nottingham: DfES Publications.

Tucker, M.S. (Ed.) (2014). Chinese lessons: Shanghai's rise to the top of the PISA league tables. Washington, DC: NCEE. Retrieved from: <http://natctr.wpengine.com/wp-content /uploads/2013/10/ChineseLessonsWeb.pdf> (20 November, 2019).

UN. (200o). United Nations Millennium Declaration. Retrieved from: https://www.ohchr.org /EN/ProfessionalInterest/Pages/Millennium.aspx (20 November, 2019).

UN. (2015). Sustainable Development Goals: Transforming our world: the 2030 agenda for sustainable development. Retrieved from: <https://sustainabledevelopment.un.org /post2015/transformingourworld > (20 November, 2019).

UN. (2017). World population prospects: The 2017 revision. World population 2017 Wallchart. United Nations Department of Economic and Social Affairs, Population Division. St/ESA/SER.A/398. Retrieved from: <https://population.un.org/wpp/Publications/Files /WPP2017_Wallchart.pdf> (20 November, 2019).

UNESCO. (2015). Education 2030. Incheon declaration. Declaration on the future of global education until 2030. Retrieved from: <http://unesdoc.unesco.org/images/oo24/oo2456 /245656E.pdf > (20 November, 2019).

UNESCO. (2016). Global education monitoring report 2016 (GEM). Education for people and planet. Retrieved from: <https://en.unesco.org/gem-report/report/2016/education-people -and-planet-creating-sustainable-futures-all > (20 November, 2019).

UNESCO. (2018). Handbook on measuring equity in education. Montreal, Quebec, Canada:

UNESCO Institute for Statistics. Retrieved from: <http://uis.unesco.org/sites/default/files /documents/handbook-measuring-equity-education-2018-en.pdf > (20 November, 2019).

UNESCO. (2018). Global education monitoring report 2019 (GEM). Building bridges not walls.

Retrieved from: <https://en.unesco.org/gem-report/report/2019/migration> (20 November, 2019).

UNICEF. (2017a). UNICEF annual report, Uruguay. Retrieved from: <https://www.unicef.org /about/annualreport/files/Uruguay_2017_COAR.pdf> (20 November, 2019).

UNICEF. (2017b). UNICEF Annual report, India. Retrieved from: <https://www.unicef.org /about/annualreport/files/India_2017_COAR.pdf> (20 November, 2019). 
Wang, Q. (2009). Primary English in China: Policy, curriculum and implementation. In M. Nikolov (Ed.), The age factor and early language learning (pp. 277-310). Berlin: Mouton de Gruyter.

World Bank. (2016). World Bank data for India, population. World Bank Group. Retrieved from: <https://data.worldbank.org/?locations=IN-1W> (20 November, 2019).

World Bank. (2019). The World Bank in Uruguay. Overview. Retrieved from: <https://www .worldbank.org/en/country/uruguay/overview> (20 November, 2019).

Yu, Z., \& Ruan, J. (2012). Early childhood education in China. In J. Ruan \& C. B. Leung (Eds.), Perspectives on teaching and learning English literacy in China (pp. 51-65). Dordrecht: Springer. https://doi.org/10.1007/978-94-007-4994-8_4

Young Lives Study. (2000-2015). Oxford: University of Oxford, Department of International Development. Retrieved from: <http://www.younglives.org.uk> (2o November, 2019).

Zhou, M. (2012). Introduction. The contact between Putonghua (Modern Standard Chinese) and minority languages in China. International Journal of the Sociolinguistics of Language, 215, 1-17.

Zou, Shuo. (2019). New policies ease access to kindergartens. China Daily, 2 January, 2019.

\section{Address for correspondence}

Janet Enever

King's College London

School of Education, Communication \& Society

Waterloo Bridge Wing, Franklin Watts Building

London SE1 9NH

United Kingdom

eneverj@gmail.com 